\title{
Die susters van die broederkerk - 'n Verhaal van vrouens in die Morawiese kerk in Suid-Afrika
}

C Landman

\begin{abstract}
The sisters of the Brethern Church. A story of women in the Moravian Church in South Africa
\end{abstract}

The story of early women converts of the Moravian Church is told. It is argued that this church, since it commenced with missionary work in South Africa in 1737, showed a positive and reconstructive attitude towards women. Presently many so-called coloured women hold high positions in the ministry and moderamen of this church. It is therefore appropriate that Nelson Mandela called his Cape Town residence "Genadendal" in commemoration of the first Moravian mission station in South Africa and the work done there for the past three centuries in service of human dignity. As such it is also appropriate to dedicate this article to Carl Borchardt for his inclusive attitude towards women colleagues.

\section{INLEIDING}

Nelson Mandela (1918-), president van 'n nuwe demokratiese regering in Suid-Afrika, het op 1 Februarie 1995 sy amptelike Kaapstadse woning na die Morawiese sendingstasie "Genadendal" vernoem". As rede hiervoor is aangevoer dat Genadendal ' $n$ simbool van hoop vir Suid-Afrikaners is omdat daar by hierdie sendingstasie sedert sy stigting samewerking tussen mense van verskillende rassegroepe was wat hulleself deur nougesette selfopheffingsprogramme verbeter het. Dit is inderdaad nou meer as 250 jaar gelede dat die eerste professionele sendeling in Suid-Afrika, Georg Schmidt (1709-1785), in 1739 saam met 'n aantal Khoikhois in Baviaanspoort 'n nedersetting begin het wat in 1804 tot "Genadendal" herdoop is en 'n model van godsdienstige en maatskaplike selfontwikkeling sou word. Voorts lui die verklaring van die president se kantoor dan dat “(d)ie naam Genadendal die Regering se voorneme (simboliseer) om alles reg te makk, weer op te bou en te laat herleef wat deur ongeregtighede geskaad is"2.

Die onderhawige artikel yoer aan dat Genadendal nie net 'n toekoms vir rassesamewerking en -opbou simboliseer nie. Genadendal is ook 'n 
teken van hoop vir vrouens sedert Georg Schmidt die Khoikhoi-vrou Vehettge Tikkuie (oorlede 1800) in 1742 gedoop het. Onder Schmidt se opvolgers het die Morawiese sendingstasies nie net 'n toevlugsoord vir hawelose Khoikhoi-vrouens op soek na 'n beter lewe geword nie, maar ook 'n sentrum van geletterdheid vanwaar vrouens uiteindelik as leiers na vore getree het. Vandag speel bruinvrouens 'n leidende rol in die Morawiese Kerk - tot in 1992 bekend as die sogenaamde Evangeliese Broederkerk - in Suid-Afrika. Frederika Goliath is die visepresident van hierdie kerk en Angelene Swart die prinsipaal van die Morawiese Opleidingskool in Heideveld in die Kaap. Tans is een van die predikante van Genadendal 'n vrou, Marthina Horak-Werz uit Duitsland. Die eggenote van die tweede predikant, Rachelle Petrus-Titus, wat in Suid-Afrika gebore en opgelei is, is self as predikant georden. Sy bedien die gemeente Hemel en Aarde wat die area rondom Caledon en Hermanus insluit ${ }^{3}$. In Mamre is Sirnobia Dampies as praktikant werksaam en in Arcadia (Port Elizabeth) Anna Michaels.

Die Morawiërs het uiteindelik sewe sendingstasies in Suid-Afrika gestig, vyf (Genadendal, Groenkloof, Enon, Hemel en Aarde, Elim) met hoofsaaklik Khoikhoilede en die laaste twee (Shilo en Clarkson) vir swartmense in die Oos-Kaap ${ }^{4}$.

Hierdie artikel handel oor die eerste vrouebekeerlinge aan die Morawiese sendingstasies van ongeveer die middel van die agtiende tot die middel van die negentiende eeu. Omdat hierdie vrouens nie self literêr geskryf het nie, moet hulle stemme uit die dagboeke en verslae van sendelinge herwin word. Die artikel laat hierdie vrouestemme veral oor drie sake praat: (a) die vrouens se reaksie op die kulturele eise van die Christendom; (b) die vrouens se belewing van geestelike skuld en verlossing; en (c) die vrouens se houding teenoor geletterdheid.

Ek dra derhalwe graag hierdie artikel aan Carl Borchardt op. As een van sy latere opvolgers aan die Departement Kerkgeskiedenis aan Unisa in Vroeë en Middeleeuse Kerkgeskiedenis en as medesekretaris van die Kerkhistoriese Werkgemeenskap van Suider-Afrika vir etlike jare het ek hom leer ken as 'n inklusiewe persoon wat vrouedosente en kollegas nooit na 'n aparte plek sou probeer wegskuif nie. 


\subsection{Georg Schmidt: sy agtergrond en houding teenoor Khoikhoi- vrouens}

Georg Schmidt was 16 jaar oud toe hy hom by 'n groepie Christene by Herrnhut aangesluit het. Dit was die jaar 17255. Hierdie groepie vlugtelinge uit Morawië het hulle in 1722 hier te Herrnhut gevestig op die landgoed van die Graaf von Zinzindorf (1700-1760). Hulle het 'n geskiedenis gehad wat teruggestrek het tot in die laat-Middeleeue toe mense in Bohemië onder Johannes Wyclif (oorlede 1384) wou terugkeer na 'n meer "Bybelse" lewenswyse. Hierdie lewenswyse het mense, en veral ook leke, aangemoedig om naby aan God te leef deur God se Woord te lees en direk en met oorgawe tot God te bid. Vir hulle uiters piëtistiese lewenswyse en oortuigings is die Herrnhutters en hulle voorgangers vervolg, eers om politieke redes en later deur Rooms-Katolieke ${ }^{6}$. Georg Schmidt het twee jaar na sy aankoms aldaar, in 1727, saam met die Herrnhuters ' $n$ verdere oplewing in hierdie godsdienstige waardes beleef en daarmee gepaardgaande die stigting van die "Hernude Broederkerk"? Weens sy sendingywer is Georg Schmidt gedurende die volgende sewe jaar telkens deur die Rooms-Katolieke owerhede aan wrede tronkstraf onderwerp. Hy is in 1734 toegelaat om na Herrnhut terug te keer, maar omdat die Herrnhutters vermoed het dat hy lojaliteit aan die RoomsKatolieke Kerk moes belowe het ter wille van sy vrylating, is hy uiteindelik na die Kaapkolonie gestuur om die Khoikhoi te bekeer en om daardeur sy ware lojaliteit te bewys.

By Baviaanspoort het Schmidt die Khoikhoi, wat reeds nie meer volledig nomadies was nie, verplig om uit die tradisionele krale te trek en op die sendingstasie te kom woon. Die inwoners van die sendingstasie is onder verpligting geplaas om van hulle groepsgebruike, soos 'n kenmerkende skamele kleredrag, dans en drank, afstand te doen en 'n meer individualistiese lewenstyl te volg in ooreenstemming met kontemporêre Duitse piëtisme ${ }^{8}$. Tog het Schmidt die Khoikhoi-gebruike gerespekteer in die werk wat hy aan veral die vrouens opgedra het. Hulle het nog steeds vir hom koringare opgetel ${ }^{9}$, wildevye gesoek ${ }^{10}$, matjiesgoed gepluk ${ }^{11}$, wortels gesoek ${ }^{12}$ en natuurlik vir hom gekook soos hulle in hulle stambestaan gedoen het. Dit lyk amper asof die vrouens by die nedersetting die slegste van twee wêrelde geërf het: aan die een kant moes hulle op die gewone harde manier die kos op die tafel kry, maar aan die ander kant was hulle uitgesluit van die plesierighede wat vrouwees in die kraal beloon het. 
Die lewe by hierdie sendingstasie was inderdaad so hard en preuts dat 'n buitestander opgemerk het: "Wie sou so kon lewe?"13.

Soos die nedersetting gegroei het, is daar mettertyd aparte godsdiensklasse vir die mans en die vrouens gehou. Ten spyte van hierdie apartheid is dit egter te betwyfel of Schmidt vir die vrouens ander dinge oor sy "Heiland", sy mees algemene benaming vir Jesus, geleer het as vir die mans. Sy boodskap was eenvoudig dit, dat ons almal van nature ewe verdoemenswaardig is ${ }^{14}$. Schmidt het die onderskeid tussen die ryk van die Here Jesus en die ryk van die duiwel teenoor mans netsoveel beklemtoon as vir vrouens. Hy kon ook telkens in sy jaarverslae aandui dat eweveel mans en vrouens sy dienste bygewoon het. Toe hy in 1743 terug Europa toe vertrek het, was daar 47 mense op die nedersetting waarvan 19 vrouens was ${ }^{15}$.

'n Mens sou derhalwe kon vra waarom mense, en veral vrouens, hulle by 'n nedersetting aangesluit het waar hulle hard moes werk, waar hulle plesier ingekort is en waar hulle met die hel gedreig is. Die verhaal van Vehettge Tikkuie is in hierdie verband relevant.

\subsection{Vehettge Tikkuie (oorlede 1800)}

George Schmidt se eerste vrouebekeerling in die Baviaanspoort (later Genadendal) was Vehettge Tikkuie wat uiteindelik op 4 April 1742 as Magdalena gedoop sou word ${ }^{16}$. Tikkuie was 'n lid van die plaaslike Khoigemeenskap wat op die banke van die Riviersonderend gewoon het; sy was getroud met Jacktie Tikkuie ${ }^{17}$. Aan haar het Schmidt die puriteinse en piëtistiese waardes van die Broederkerk oorgedra: 'n Christen moet, gedagtig aan Christus se verskriklike lyding, self bereid wees tot "lyding", dit is, tot ' $n$ meedoënlose selfdissipline. Hierdie totale toewyding aan Christus sluit in dat Christene hulle van die wêreld sal onderskei en hulle lewe sal toewy aan die lees van die Bybel en die herkenning van God se wil.

Tikkuie se reaksie op hierdie teologie is slegs beskikbaar in die woorde van George Schmidt self soos hy dit in sy dagboek opgeteken het: Tikkuie voel, in die eerste plek, ambivalent oor die verlies aan kultuurgoed. Herhaaldelik kla sy by Schmidt dat "die volk teen haar is", dat haar vriende en familie haar verwerp omdat sy nou by die sendeling bly ${ }^{18}$; sy smeek vir sy verstaan en simpatie, maar Schmidt jaag haar weg. Kultuurgoed is ononderhandelbaar. Sy kan nie 'n piëtistiese Christen wees terwyl sy by die krale gaan dans en drink nie. Tweedens het Tikkuie se geestelike skuldgevoelens vinnig en sterk ontwikkel onder die piëtisme. Sy 
is bang vir die hel. Schmidt dreig haar daarmee en sy gee in. Sy sien nie kans vir 'n plek van ewige straf waaruit sy nooit sal kom nie ${ }^{19}$. Sy laat haar in die "bloed en dood" van Jesus doop. Haar doop was eenvoudig en eensaam. Dit staan in die teken van totale isolasie nie net van kraal nie, maar ook van gemeente. Schmidt staan enkele reëls in sy dagboek af om dit op te teken:

"Die 4de (April 1742). Vanoggend het 8 gekom vir lees en voorlesing. Daarna het ek Vehethgien na my toe laat kom en met haar gepraat en haar gevra of sy in die bloed en dood van Jesus gedoop wil word. Sy het gesê: 'Ja'. Toe het ek aan haar verduidelik wat die doop beteken. Daarna het ek aan haar die vrae voorgehou wat ek aan broeder Josua gerig het. Sy het hulle almal met 'Ja' geantwoord. Toe het ek met haar na die water gegaan en haar gedoop. Haar naam is nou Magdalena" 20.

'n Mens sou dan, derdens, die vraag kon herhaal waarom vrouens soos Tikkuie hulle dan überhaupt by die sendingstasie aangesluit het. Een rede is geleë in die feit dat die vrouens, soos die mans, deur die sendeling bewus gemaak is van skuld en 'n hel wat wag en dat die vroeëre naïwiteit, veral in die geval van 'n gevoelige mens soos Tikkuie, verloor is. 'n Belangriker rede was egter die aantreklikheid van geletterdheid. Schmidt het die mense op die sendingstasie, mans en vrouens, leer lees en skryf. Dit sou in die toekoms ' $n$ belangrike rol in die menswaardigheid van gekolonialiseerde en veral geslaggestileerde mense speel.

$\mathrm{Na}$ Schmidt se vertrek in 1743 , het die gemeente feitlik verdwyn. Toe 'n volgende geslag Morawiese sendelinge vyftig jaar later in die betrokke gebied aangekom het, is ' $n$ bejaarde Tikkuie in haar tagtigs (op 24 Desember 1792) na die sendelinge gelei. Sy het 'n Bybel, 'n geskenk van Schmidt, by haar gehad waaruit sy nog kon lees. Tikkuie het oor 'n halfeeu heen vasgeklou aan die geletterdheid wat Schmidt haar gegee het; sy het volgehou om so te lewe dat sy haar gewete en die hel sou vryspring; sy kon egter, volgens die sendelinge, min van Jesus onthou, behalwe dat hy aan die kruis vir ons sondes gesterf het ${ }^{21}$.

Vyf dae voor die inwyding van die nuwe kerk, op 3 Februarie 1800, is Tikkuie oorlede.

\subsection{Marsveld, Schwinn and Kühnel en die hawe vir haweloses}

Georg Schmidt was 'n bietjie onsimpatiek maar tog affirmatief teenoor vrouens. Hy was opreg, maar het tog 'n bietjie aan 'n vervolgingspiëteit 
gely. Die drie mans wat hom as sendelinge opgevolg het in 1792 was anders. Hulle was vrouvriendelik en het Genadendal letterlik in 'n hawe vir vervolgde vrouens omskep. In Januarie 1793 heropen Hendrik Marsveld (1745-1822), Daniël Schwinn (geb 1750) en Christian Kühnel (1862-1813) die sending op Genadendal. Op 12 Maart is daar die volgende inskrywing in hul dagboek:

"Op die 12de het 'n jong Khoikhoi-vrou na ons toe gekom en gesê dat die boer vir wie sy noual twee jaar werk, haar geslaan het toe sy vir hom gesê het dat sy wil kom leer. Hy het gesê dat hy haar sal kom haal as sy sou wegloop. Ons het vir haar gesê dat as sy niks verkeerds gedoen het nie, sy hier in een van die krale kon bly en dat die boer haar waarskynlik nie sal kom haal nie. Dit het egter al in die verlede gebeur dat die boere hiernatoe gekom het en die Khoikhoi verskriklik geslaan het. Op die oomblik bly sy nog hier. Daar het ook nog drie ander gekom wat saam met haar wil leer" 22 .

Hierdie insident van Khoikhoi-vrouens wat van die plase weggeloop het omdat hulle diensgewers hulle nie wou laat leer het nie, het homself telkens op Baviaanskloof/Genadendal herhaal. Twee dae na bogenoemde insident (op 14 Maart) vertel die dagboek dat 'n boer 'n vrou se tweemaande-oue baba van haar weggevat en by hom gehou het omdat hy nie wou gehad het dat sy moes "gaan leer" nie. "Gaan leer" het in hierdie sin nie net beteken om van God se wil te leer nie, maar ook om te leer lees en skryf. Vrouens wie se mans hulle nie wou laat leer nie, is ook op die sendingstasie geakkommodeer (11 April 1793). Vrouens wat by die sendingstasie wou kom leer, maar wie se mans slawe was en op die plase moes agterbly, is met groot simpatie behandel en van hulp voorsien ${ }^{23}$. Die landswet was dat wanneer 'n slaaf met 'n Khoikhoi-vrou trou, die kinders vir die eienaar moes werk totdat hulle 25 jaar oud was. Toe die wet verander is sodat die kinders aan die ma behoort het, het die sendelinge begin om hierdie kinders, en gewoonlik het dit vir dogters gegeld, teen boere te beskerm wat hulle wederregtelik wou opeis ${ }^{24}$.

Mans op die sendingstasie is nie toegelaat om hulle vrouens te slaan nie. Toe 'n Khoikhoi-man sy vrou geslaan het (14 Maart 1793) omdat sy nie sy broek wou regmaak nie, is hy vermaan dat God se kinders nie aan 'n vrou slaan nie. Toe hy hom nie daaroor wou skaam nie, is hy gevra om te loop en die ander Khoikhoi-mans is op die onaanvaarbaarheid van vroueslanery gewys. Khoikhoi-vrouens wat die wit boere se minnaresse was en tot bekering gekom het, kon ook op die sendingstasie se beskerming 
reken ${ }^{25}$. Baie simpatieke en persoonlike aandag is ook aan vrouens gegee wat siek of hulpeloos was. Op 9 Maart 1794 word 'n briefie vir 'n sterwende vrou geskryf sodat sy dit onder haar kussing kan sit en saamneem na haar baba in die hemel wat vier dae tevore oorlede is.

Khoikhoi-vrouens het dus vroeg reeds na Baviaanspoort/Genadendal gekom in redelike groot getalle, tot 30 op 'n keer en daagliks in groeiende getalle. Hulle het gekom om te leer van God, van lees en skryf, en van menswaardigheid. Hulle was bereid om aan die kulturele eise wat aan hulle by die sendingstasie gestel is, te voldoen wat nie meer so genadeloos was soos in Schmidt se tyd nie. En hulle was ontvanklik vir die piëtistiese boodskap wat toe nog steeds op die hel en op Christus se kruis en bloed gekonsentreer het. Op 'n doopvraag (5 Maart 1794) waarom hulle dankbaar moet wees teenoor hulle Verlosser, het die doopkandidate geantwoord: "Omdat hy homself aan die kruis laat vasspyker het en sy bloed vir my sondes laat vloei het, sodat ek verlos kan word van die ewige verdoemenis...".

\subsection{Hanna, die dogter van Kibido (f1 1793)}

Op 19 Julie 1793 het bogenoemde drie sendelinge hulle eerste doopkandidaat gedoop. Dit was Hanna, die dogter van Kibido, wat gedoop is as Anna Maria Mauritz. Kibido is vyftig jaar tevore, 'n week na Vehettge, deur Georg Schmidt as Jonas gedoop. Teen die einde van 1793 was daar by die sendingstasie sewe gedoopte vrouens, Tikkuie ingesluit ${ }^{26}$.

Uit die brokkies wat beskikbaar is oor Hanna se doop, is dit duidelik dat transkulturele aanpassing vir haar makliker was as vir Tikkuie vyftig jaar tevore. By haar doop 27 was daar ongeveer 78 mense. Sy het die ondersteuning van die mense gehad wat vir haar wit klere geleen het om aan te trek. Syself het gewilliglik al haar krale afgehaal om daarmee met haar Verlosser te identifiseer wat nie sy nek met krale versier het nie, maar met sy heilige bloed.

Net voor haar doop het Hanna 'n droom gehad28. In die droom het sy haarself in wit klere gesien staan voor die preekstoel. Die sendeling, haar leermeester, was ook in wit geklee en gereed om haar te doop. Die hele gemeente het op hulle knieë neergeval, gebid en gesing. Die Heilige Gees het aan haar die betekenis van alles bekendgemaak.

Uit hierdie droom word dit duidelik, eerstens, dat Hanna haar ou lewe maklik agter haar gelaat het met die ondersteuning van die vergrote gemeente (anders as Tikkuie wat in eensaamheid haar stryd moes stry). Tweedens val die prominente rol van die sendeling as onderwyser op. 
Derdens word ons bewus van die rol van die Heilige Gees in Hanna se piëtisitiese bewussyn.

\section{ROSETTA (BENIGNA) VAN GROENEKLOOF OF MAMRE (1752-1854)}

Die verhaal van Rosetta in Benigna van Groenekloof of Mamre, een verhaal voor de Christen Kleurlinge van Zuid-Afrika door een hunner leeraars (1873) begin dramaties. Die sewejarige Rosetta, dogter van die stamvader Jantje Klapmuts, staan met haar oor teen die halfoop deur van die plaasskooltjie. Sy luister af. Sy luister na die drie r'e en na die Nuwe Testament. Dis vir haar wonderlik. Maar iemand sien haar van binne en jaag haar weg met 'n "Loop, Rosetta!". In die volgende 50 plus jaar woon en werk Rosetta op verskillende plase en is sy getroud met verskillende mans. Uiteindelik, in 1813, trek sy na Groenekloof wat pas in 1810 op die grond van haar onwillige broer, Hans Klapmuts, gestig is. In 1814, toe sy 62 jaar oud was, word Rosetta gedoop en Benigna genoem.

Teen die tyd dat Rosetta na Groenekloof gaan, is daar reeds 200 Khoikhois in 40 huise woonagtig. Vrouens stroom na Groenekloof, al moes baie van hulle hulle besittings op die plase agterlaat, soos Trijn, Judith en Margaretha getuig29. 'n Mens sou weer eens kon vra hoekom. Die redes wat die vrouens (via die sendeling) gee, is geestelik. Hulle is bang vir die gevolge van hulle geestelike skuld. Nadat ek God se woord gehoor het, het ek onrustig en angstig geword, sê Elsje ${ }^{30}$, want daar is geen sonde wat ek nog nie gedoen het nie. Ek is dankbaar dat God my my vele sondes vergewe het, sê Rachel ${ }^{31}$. Ek het nou genoeg vir die sonde gelewe, nou gaan ek vir my siel sorg, sê Leentje ${ }^{32}$. Die verhaal van Rosetta toon egter dat hierdie vrouens nie naïef was oor die sosiale voordele wat 'n verblyf aan Groenekloof vir hulle ingehou het nie gedurende 'n tyd toe die "swart" gemeenskap aan sosiale verval blootgestel was wat gedeeltelik aan die wit kolonialisering van die Kaap en omgewing toegeskryf kan word.

Rosetta (Benigna) gaan na Groenekloof, volgens die sendeling, om gedoop te word. Leer en bid is nie meer genoeg nie, sy voel sy moes ook nog gedoop word ${ }^{33}$. Volgens die sendeling moes Rosetta van 'n sekere mate van rykdom afstand doen om na Groenekloof te kon gaan. Tog kon 'n ander rede ook waar gewees het. Rosetta gaan na Groenekloof wanneer sy eintlik te oud is om vir haar werkgewer op die plaas van nut te wees. Vanaf 1808 het daar glo verskeie dinge gebeur wat Rosetta oortuig het dat dit God se wil was dat sy na Groenekloof gaan: sy oorleef 'n aanval op hulle huis gedurende die slaweopstand (1808) en 'n aardbewing in 1809. In 
1813 trek Rosetta en haar vier kinders (10 van haar kinders het reeds gesterf) na Groenekloof. Daar bou sy 'n huis en maak tuin. Nou het sy 'n plek waar sy "ongehinderd haar sielsbelange kan behartig" ${ }^{44}$. Sy het ook 'n plek waar daar vir haar op haar oudag gesorg sou word. 'n Mens kan daarop let dat sy, in haar antwoord as doopkandidaat haar toewy aan 'n piëtistiese lewenswyse hier op aarde, maar dat die belofte van ewige lewe na die dood ook baie sterk by die bejaarde vrou figureer: "Vir Jesus wil ek lewe. Vir Hom wil ek liefhê. In Hom wil ek sterwe en as sy kind begrawe word".

Rosetta was toe reeds 62 jaar oud en sy is dankbaar om 'n plekkie op Groenekloof te hê waar sy in die arms van familie en gemeentelede haar laaste jare kan deurbring. Ten spyte van haar ouderdom noem sy haarself, binne die piëtistiese raamwerk, "'n swakke kind". Sy maak vriende met die ouer mense op die sendingstasie by wie sy emosionele ondersteuning kon kry. Susanna is haar vriendin. Susanna se kenmerk is dat sy nooit kla nie en vir alles, ook haar komende sterfte, vir God dankbaar is ${ }^{35}$. Wanneer Rosetta self deur sendeling Schmidt op 17 Julie 1814 gedoop word, pas ses maande na haar aankoms by Groenekloof, verbly sy haar in haar nuwe naam, Benigna, wat op dankbaarheid teenoor God dui.

Die skrywer van Benigna van Groenekloof of Mamre haal Rosetta se reaksies op haar doop telkens woordeliks aan. Natuurlik weet ons nie of dit werklik haar woorde was nie. Uit hierdie aanhalings blyk dit egter wat die ideaal was wat aan 'n gedoopte Morawiese vrou in hierdie tyd gestel is en waaraan Rosetta waarskynlik bereid was om te voldoen. Eerstens kan gelet word op die inhoud wat aan 'n piëtistiese lewenswyse gegee is: armoede is verkieslik bo "wêreldse goed"; dankbaarheid vir die dinge wat self gekweek en gebou word, is oorvloedig. Ook is daar dankbaarheid vir die aflossing van geestelike skuld. Ek is dankbaar dat my Heiland my hiernatoe gebring het, sê die bejaarde Rosetta; hier word al my sondes my vergewe. Tweedens is dit opmerklik dat Rosetta haar ou kultuur, haar ou familie, soos haar broer Hans en sy mense wat nou volledig landbouers geword het, tog kon agterlaat, hoewel onwillig. Sy trek met haar nuwe familie, haar kinders, na Groenekloof. Derdens slaan Rosetta geen godsdiensoefening oor nie. Sy gaan onverpoosd voort om van God te leer en van Hom te lees ${ }^{36}$. Tussen die lyne van die verhaal is dit egter duidelik dat Rosetta by Groenekloof beskerming en hulp gekry het wat sy nie elders op haar oudag sou gekry het nie.

Rosetta sterf toe sy 102 jaar oud is, in 1854 , die jaar toe Groenekloof tot Mamre hernoem is. Voor haar dood was sy vir dekades feitlik 'n invalide. 
Wilhelmina Stompjes het haar die lot van haar swart stamgenote in die Oos-Kaap sterk aangetrek. Toe Christian Ignatius Latrobe, die sekretaris van die hoofbestuur van die Morawiese Kerk, Genadendal in 1816 besoek het $^{37}$, het sy daar 'n gesprek met hom aangevra ${ }^{38}$. Weer eens kan die voorgeskrewe piëteit van die tyd en konteks uit hierdie gesprek afgelei word. Eerstens spreek Stompjes haar bekommernis uit oor die "donkerte" waarin haar mense lewe waarin hulle die prooi is van die kwade en die sonde. Sy vra die sekretaris vir onderwysers om hulle te leer (lees) van God. Sy konfrontreer die sekretaris met Jesaja 42:16 op grond waarvan sy hoop op iemand wat haar mense uit hulle blindheid na die verlossing van Christus sal lei. Eintlik vra sy ook vir geletterdheid. Tweedens kom die aard van haar piëtiet na vore in haar herhaaldelike beklemtoning, volgens Latrobe se verslag, van haar eie nederige en sondige toestand. Net in Jesus vind sy vreugde.

Derdens vind ons in hierdie gesprek 'n sterk politieke bewussyn by Wilhelmina Stompjes. Toe die sekretaris op haar versoek reageer deur daarop te wys dat dit nie vir sendelinge veilig is om die Oos-Kaap binne te gaan terwyl daar oorlog tussen wit en swart is nie, antwoord sy in die woorde van Latrobe se verslag:

"that the best way to begin a Mission would be, to send one or more Caffres to King TeGeika, and inform him of the aim of such an institution; and though she believed, that just now the Caffres might kill the boors for robbing them of their land, they would protect Missionaries coming from Gnadenthal; that a settlement might be formed, by the Caffre part of this congregation becoming the first settlers in any part of their country, suitable for the purpose, and that, if a mission were begun, and succeeded, there would be an end of all Caffred-wars with the English".

Hierdie drie kenmerke, 'n piëtistiese lewenshouding, 'n bewussyn van die donkerte van onkunde en 'n verband tussen geletterdheid en politieke bewussyn sou tot op hede kenmerkend van 'n prominente aantal Morawiese vrouens bly. 


\section{SLOT}

Die eerste vroue-bekeerlinge van die Morawiese Kerk, dit is, die eerste susters van die Broederkerk in Suid-Afrika, het hulle ernstig gesteur aan die sendelinge van hierdie kerk se opvattings oor skuld en verlossing, oor hemel en hel, en oor wat reg en verkeerd is. Hulle was bereid om vir hierdie soort godsdienstige bewussyn, dit is, vir kontemporêre piëtisme, sigbare opofferings te maak soos om hulle kleredrag en selfs hulle blyplek te verander. Hierdie vrouens was egter nie sosiaal en polities naïef nie. Hulle het besef dat ' $n$ verbintenis met die sendingstasies vir hulle sosiale voordele inhou soos die aanleer van geletterdheid en die beskerming en versorging van 'n gelykdenkende groep. In een geval het ons gesien dat 'n vrou die politieke doelstellings van sendingwerk gelykgestel het aan die vrede wat dit tussen bevolkingsgroepe sou bring.

Vrouens wat vandag leidende posisies in die Morawiese Kerk in SuidAfrika speel, toon karaktertrekke wat ooreenkom met dié van hulle eerste voormoeders. Hulleself lewe op sosiale en geloofsvlak volgens behoudende waardes wat nie 'n agtiende-eeuse piëteit in die steek gelaat het nie. Op die vlak van geletterdheid kombineer hulle hulle geleerdheid met 'n sterk politieke bewussyn. Dit kan afgelei word, onder andere, uit die finalejaarskripsie waarin Rachelle Petrus-Titus 'n feministiese evaluering van haar kerk gegee het. Dit kan verder afgelei word uit die werk wat Angelene Swart as prinsipaal van die Morawiese Opleidingskool gedoen het en beplan om te doen; sy doen 'n kritiese ondersoek na die verband tussen die besluit van die Morawiese Kerk in 1992 om sy twee provinsies (Wes- en Oos-Kaapland) te verenig en 'n feministiese bevrydingsteologie.

Dit is hierdie susters en ander soos hulle wat gesorg het dat hierdie kerk sedert 1992 nie meer as die Broederkerk bekendstaan nie. Die Morawiese Kerk in Suid-Afrika is immers reeds vanaf sy bestaan 'n Broeder- en 'n Susterkerk in een.

\section{NOTAS:}

1 Dit het voorheen Westbrooke geheet.

2 Die Beeld, 1 Februarie 1995.

3 Die Morawiese gemeente Hemel en Aarde sluit Caledon, Hermanus, Botrivier, Karwyderskraal en Hauston in.

4 Genadendal is ongeveer 100 kilometer $\infty$ s van Kaapstad geleë met Caledon as die naaste groot dorp. Dit het in 1739 tot stand gekom het en in 1804 sy huidige 
naam gekry. Tans woon daar hoofsaaklik bruinmense. Groenekloof heet tans Mamre en lê ongeveer 45 kilometer noord van Kaapstad. Daar woon ook tans hoofsaaklik bruinmense en is in 1810 gestig. Enon, naby Kirkwood, 50 kilometers noord van Uitenhage, is in 1820 gestig en is ook vandag 'n bruin gemeenskap. Elim, gestig in 1823, is die mees suidelike Morawiese sendingstasie en naby Kaap Agulhas geleë met tans 'n hoofsaaklik bruin gemeenskap. In 1823 is ook 'n hospitaal vir melaatses naby die mond van die Onrusrivier gebou met die naam Hemel en Aarde. Shiloh, in die Oos-Kaap naby Whittlesea, 70 kilometers noord van Fort Beaufort, is in 1828 vir die Thembus ("Tambookies") gestig. Clarkson in die Oos-Kaap naby Plettenbergbaai en gestig in 1839, het oorspronklik Fingoe-inwoners gehad maar bestaan tans uit 'n hoofsaaklik bruin, Afrikaanssprekende gemeenskap. Die Fingoes, wat vroeër hierdie eeu na die Transkei verskuif is, keer tans terug na hulle oorspronklike grondgebied by Clarkson. Sommige van hulle is nog Morawiërs.

5 H C Bredekamp \& J L Hattingh, Das Tagebuch und die Briefe von Georg Schmidt, dem ersten Missionar in Südafrika (1737-1744), Bellville 1981, 18.

6 B Krüger, The beginnings of the Moravian church, Genadendal 1956.

7 B Krüger (ed), Die graaf van Zinzendorf, die stigter van die Hernude Broederkerk, Genadendal: 1956.

8 G Schmidt, Dagboek en briewe. Geredigeer deur H C Bredekamp \& J C Hattingh, Belville 1839-1743/1981.

9 Schmidt, 105.

$10 \quad A w, 109$.

$11 \quad A w, 111$.

$12 \quad A w, 113$.

$13 A w, 221$.

14 Byvoorbeeld Schmidt $a w, 221$.

$15 \quad A w, 497$.

16 Georg Schmidt het vyf mense gedoop gedurende sy verblyf te Baviaanspoort van 1739 tot 1744: Willem op 31 Maart 1742 wat as Josua gedoop is; Afrika is op 2 April as Christian gedoop; op 4 April 1742 is Vehettge Tikkuie gedoop en Magdalena genoem; op 12 April is 2 mense gedoop, Kibido as Jonas, en die suster van 'n sekere Moses as Christina (George Schmidt en sy opvolgers: 200 jaar Evangeliese Broederkerk (Moravian Church) in Suid-Afrika: 1737-1937, sl, sn, 19-). 
17 Daar is reeds twee moderne opstelle oor Vehettge Tikkuie se lewe geskrywe waarvan laasgenoemde van eersgenoemde afhanklik is: H C Bredenkamp, "Vehettge Tikkuie, alias moeder Lena van Genadendal, 1739-1800", Kwartaalblad van die Suid-Afrikaanse Biblioteek 41/4 (1987), 134-141. Asook A Swart, "The story of Vehettge Tikkuie" in: Digging up our foremothers. Stories of women in Africa, Pretoria 1995. 'n Ouer verhaal is dié van R Schmidt, Die ou suster Magdalena; een van die dopelinge van die leraar George Schmidt in Baviaanskloof, Genadendal 1937.

18 Schmidt, $a w, 73,87,101,103,207,239,245$, ens.

19 Schmidt, $a w, 73$.

$20 \quad A w, 345$.

21 H C Bredekamp \& H E F Plüddemann (ed), The Genadendal Diaries I, Bellville 1792-1794/1992, 59-61. Op 26 Junie 1793 voer die sendelinge 'n gesprek met "Ou Lena" waaruit hierdie drie punte weer blyk: haar dringende soeke na geletterdheid, haar verlange na die hemel en haar spyt omdat sy altyd 'n stryd moes voer om die gebruike van haar vroeëre lewe af te lê. (Vergelyk $a$ $w, 109-110)$.

22 Bredenkamp \& Plūddemann, $a w, 79$ (my vertaling).

$23 \quad A w, 126$.

$24 \quad A w, 184$.

$25 A w, 192$.

$26 \quad A w, 167$.

27 Soos beskryf in die Genadendal diaries, 117.

28 Dit word oorvertel deur $\mathrm{J}$ de Boer \& $\mathrm{E} \mathrm{M}$ Temmers, The unitas fratrum, Genadendal 1987, 12 uit 'n onbekende werk van L R Schmidt.

29 Benigna van Groenekloof of Mamre 1873, 26.

$30 \quad A w, 16$.

$31 \quad A w, 22$.

$32 \quad A w, 23$.

$33 \quad A w, 29$. 
$34 \quad A w, 34$.

$35 A w, 35$.

36. A w, 36-37.

37 I Balie, Die geskiedenis van Genadendal 1738-1988, Kaapstad 1988, 29.

38 Opgeteken in C I Latrobe, A journal of a visit to South Africa, London 1821, 96-97. 